\title{
Erratum to: Impacts of ruminal microorganisms on the production of fuels: how can we intercede from the outside?
}

Paul J. Weimer ${ }^{1,2} \cdot$ Richard A. Kohn ${ }^{3}$

Published online: 10 March 2016

(C) Springer-Verlag Berlin Heidelberg 2016

Erratum to: Appl Microbiol Biotechnol (2013) DOI 10.1007/s00253-016-7358-2

The original version of this article inadvertently contained a mistake.
Figure 1 of the published article was an earlier version of the figure that did not include the reduction of SCFAs to their corresponding alcohols or alkanes. The figure legend remains unchanged.

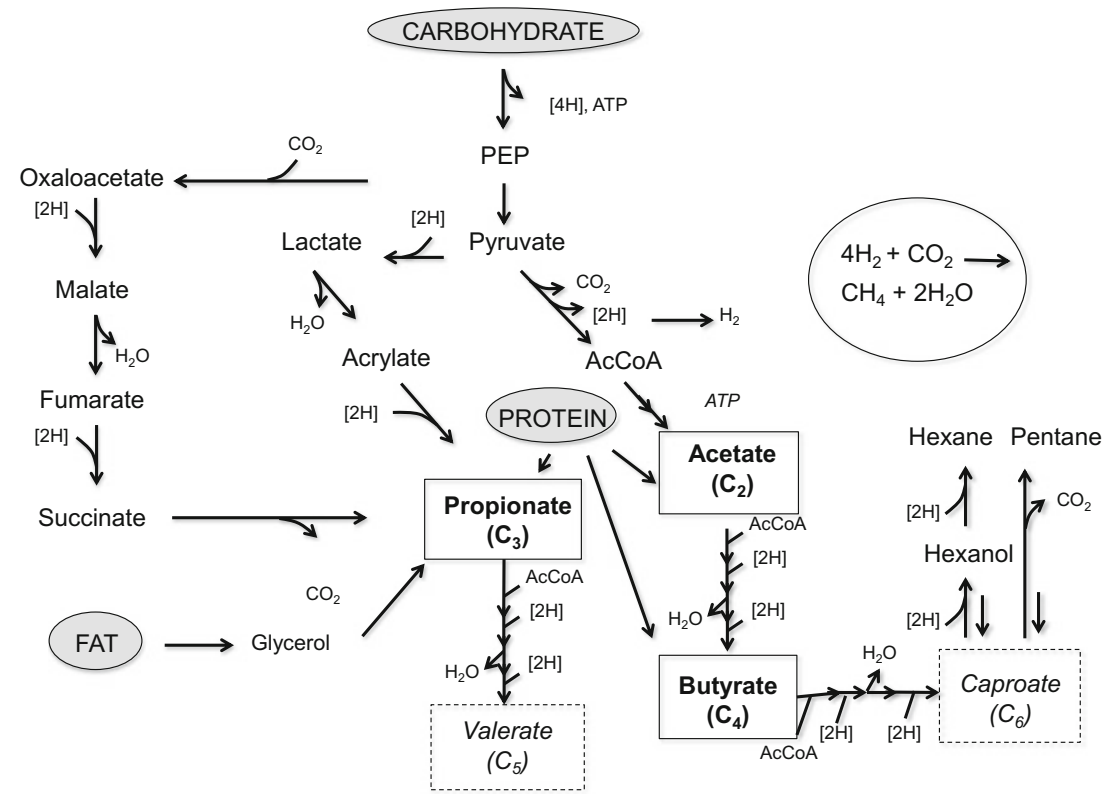

The online version of the original article can be found at http://dx.doi.org/ 10.1007/s00253-016-7358-2.

Paul J. Weimer

Paul.Weimer@ars.usda.gov

1 United States Department of Agriculture, Agricultural Research Service, US Dairy Forage Research Center, 1925 Linden DriveWest, Madison, WI 53706, USA

2 Department of Bacteriology, University of Wisconsin-Madison, Madison, WI 53706, USA

3 Department of Animal and Avian Sciences, University of Maryland, College Park, MD 20742, USA 